\title{
OS AFETOS E O CAPITALISMO
}

Alyson Freire

ILLOUZ, Eva. O amor nos tempos do capitalismo. Trad. Vera Ribeiro. Rio de Janeiro: Zahar, 2011.

"Com efeito, o sistema capitalista penetra muito mais profundamente em nossa existência". Michel Foucault, 2002, p. 124-5.

Pode-se supor que sentimentos, emoções e afetos não dizem respeito à sociologia, que eles não integram o campo de problemas e preocupações inerentes a esta disciplina. À sociologia interessaria apenas aqueles fatos sociais cuja existência dar-se-ia "fora das consciências individuais", como preconizava Emile Durkheim. Nesse sentido, os fenômenos da vida afetiva tratar-se-iam de temas estrangeiros, residuais, menores ou mesmo "nãosociológicos".

Para Eva Illouz, autora do livro em questão nesta resenha, essa visão caricata que alimenta a opinião corrente sobre a sociologia é enganosa. A socióloga marroquina, logo na abertura de $O$ Amor nos tempos do Capitalismo (2011) justifica seu projeto de uma sociologia dos afetos na constatação das "numerosas referências" aos sentimentos e afetos presentes nas narrativas e relatos clássicos da disciplina sobre a modernidade e o advento do capitalismo industrial: a alienação do trabalho capitalista como perda do vínculo com a realidade, em Marx; os sentimentos religiosos de angústia e dúvida dos protestantes como motivação da ação econômica capitalista, em Weber; a estimulação frenética da vida nervosa e as atitudes blasé do indivíduo nas metrópoles modernas, em Simmel e, por último, a solidariedade social e a efervescência coletiva em Durkheim (ILLOUZ, 2011, p. 7-8).

Se avançarmos no espectro do tempo da produção sociológica, encontraremos mais exemplos de referências a respeito das emoções na sociologia: Norbert Elias (1994; 2001), Anthony Giddens (1994), Niklas Luhmann (1991) e Viviane Zelizer (2011), só pra citar nomes e trabalhos bem conhecidos em geral.

Convidada a ministrar as prestigiadas Conferências Adorno em Frankfurt, o livro é resultado das três conferências realizadas por Illouz no histórico Instituto de Pesquisas Sociais 
no ano de 2004. Nelas, a socióloga realiza um balanço sistemático dos interesses, preocupações e perspectiva teórica que conduzem o seu trabalho até então.

A estréia de Illouz em idioma nacional, portanto, não poderia ser mais acertada, pois brinda-nos com o que podemos considerar uma introdução a sua obra e à sua abordagem sociológica no campo dos afetos, desenvolvida desde final dos anos 90 em livros como Consuming the Romantic Utopia: Love and the Cultural Contradictions of Capitalism e Oprah Winfrey and the Glamour of Misery: An Essay on Popular Culture - ambos premiados como o "Melhor Livro" pela Associação Americana de Sociologia, respectivamente em 2000 e 2005 nas seções "Emoções" e "Cultura".

Eleita em 2009 pelo periódico alemão Die Zeit como um dos intelectuais capazes de mudar o panorama do pensamento no futuro, Eva Illouz pode até ser, por enquanto, um nome pouco conhecido no cenário intelectual brasileiro, mas trata-se de uma autora, como atestam suas premiações, já consolidada internacionalmente.

O itinerário das três conferências, avaliadas em seu conjunto, destaca-se pela habilidade apresentada por Illouz em manejar e conjugar uma série variada de informações e dados. Em suas mãos, elementos dispersos como as primeiras palestras de Freud nos Estados Unidos em 1909, os experimentos do psicólogo Elton Mayo nas fábricas, a autobiografia da atriz Jane Fonda, trechos de manuais de psicologia das organizações e de descrições de empresas e entrevistas com usuários de sites de relacionamento na internet ganham um sentido sociológico e cultural revelador.

Seu objetivo com esse amplo material de análise é conduzir o leitor rumo a um crucial e intricado problema histórico-cultural, a saber: qual o papel do empoderamento institucional e cognitivo dos afetos e das emoções pela psicologia no desenvolvimento de uma cultura afetiva cujo repertório de concepções e técnicas alterou significativamente, num plano teórico e prático, os modos de percepção do eu, a relação com a própria biografia e as interações interpessoais na modernidade tardia?

De acordo com Illouz (2011, p. 11), durante o século XX, a concentração sistemática sobre a vida afetiva e as emoções ascendeu como uma dimensão socialmente marcante para mobilização e relacionamento do "eu". Os gestores no ambiente do trabalho, os produtores culturais, ativistas na sociedade civil ou os próprios indivíduos na família e em suas relações pessoais dedicaram cada vez mais esforços e atenção para assimilar a sua atividade e 
experiência esta disposição como uma verdadeira bússola para suas decisões, autocompreensões e aspirações.

Essa ascensão do homo sentimentalis, da vida afetiva e das emoções como personagens centrais da sociabilidade na modernidade tardia, possui sua gênese, segundo Illouz, no ingresso dos psicólogos e na institucionalização de seu repertório de discursos e técnicas em variados âmbitos da vida social. O empoderamento dos afetos pelo discurso e pela ação institucional dos psicólogos produziu uma cultura afetiva especializada que está, entre outros fatores, na origem das drásticas mudanças pelas quais passaram as esferas do trabalho, da família, da cultura popular, das relações amorosas e as distinções de gênero nos Estados Unidos ao longo do século XX.

Para Illouz, os afetos compõem uma das dimensões motivacionais da ação. Eles são como uma "energia interna" impulsionadora do agir, e que, na prática, se entrelaçam com significados e padrões culturais, relações sociais e instituições (Ibid., p. 9). É por essa razão que os afetos, segundo Illouz, podem iluminar aspectos pouco explorados da modernidade e da organização do capitalismo.

$\mathrm{Na}$ primeira conferência, Illouz trata da institucionalização da psicologia e da linguagem terapêutica no mundo do trabalho e cooperativo enquanto uma importante ferramenta na seleção, gestão e avaliação do desempenho dos trabalhadores. Num contex to de transformações institucionais do capitalismo, na transição entre a chamada época de ouro do capitalismo e a formação duma economia de serviços, os psicólogos operaram como experts em desenvolver ideias e procedimentos a fim de aprimorar as relações humanas no mundo das organizações, substituindo ou rivalizando com o discurso da racionalidade técnicoadministrativa dos engenheiros.

Essa intervenção dos psicólogos na gestão do processo de produção e organização do trabalho redefiniu a hierarquia de competências profissionais socialmente desejáveis e exigidas pela empresa capitalista. O centro gravitacional do bom comportamento produtivo e profissional - de gestores e trabalhadores - passa então a repousar em capacidades e atributos atrelados à personalidade, como a "comunicação", "cooperação", "empatia" ou "escuta atenta".

O agenciamento entre psicologia e empresa capitalista introduz, de modo radical, os afetos e os conteúdos emocionais no interior da dinâmica do comportamento econômico e da ação instrumental. Os afetos e as relações interpessoais são, no mesmo movimento, 
impregnados pelos repertórios do mercado e pela lógica do cálculo, desempenho e eficiência da racionalidade econômica. A essa "cultura em que os discursos e práticas afetivos e econômicos moldam uns aos outros" (Ibid., p.12), Illouz nomeia de "capitalismo afetivo".

A recusa da oposição entre estes supostos "mundos hostis", como diria Viviane Zelizer acerca do mundo do dinheiro e dos laços íntimos, ganha força de realidade na descrição de Illouz a partir de como a psicologia construiu intersecções entres esferas sociais diferenciadas, como a do mercado e a das relações amorosas. A desconstrução do dualismo capitalismo e afetos é um dos principais méritos do livro e da abordagem sociológica nele proposta.

$\mathrm{Na}$ segunda conferência, Illouz investiga as raízes culturais dessa nova cultura afetiva, responsável por reconfigurar a linguagem e a experiência da individualidade. Concomitante à consolidação das categorias psicológicas no ambiente de trabalho, o discurso terapêutico em sua expansão nos setores da classe média norte-americana adquire força e corpo numa colaboração inesperada com práticas e repertórios culturais diversos; como a literatura de aconselhamento, a cultura de consumo, os grupos de apoio e o feminismo. Dentre esses repertórios, um, em particular, destaca-se como uma fonte fundamental de referência: a psicanálise.

A psicanálise introduz na cultura do século XX uma forma completamente diferente de olhar e manejar o "eu”. É sobre esta singularidade cultural da psicanálise, segundo Illouz, que se edifica uma nova cultura da afetividade, bastante distinta em seu repertório e concepções da linguagem moral vitoriana do caráter do século XIX.

Com a psicanálise, um conjunto novo de ideias e imagens, como o papel do inconsciente e o peso da família e da sexualidade no destino do indivíduo, espiralam em setores estratégicos da cultura e da vida cotidiana norte-americanas, causando uma significativa e pragmática mudança nas concepções e ideais comuns de "eu" e nos modos de perceber e se posicionar nas relações sociais vigentes.

A institucionalização de algumas dessas ideias em formas sociais mercantilizadas e práticas culturais forma a base social e cognitiva de um verdadeiro esquema cultural compartilhado. Illouz o intitula de "estilo afetivo terapêutico": uma matriz cultural formada por esquemas de compreensão, práticas sociais e técnicas ajustadas a apreender e gerir os afetos, o "eu" e suas relações significativas.

Sua expansão e consolidação na cultura e sociedade norte-americana são tributárias da convergência e aliança da psicanálise com duas lógicas culturais decisivas: o feminismo e a 
literatura de autoajuda. Tanto um como a outra, sustenta Illouz, sintetizaram em seus credos culturais, ideias da psicanálise e das novas teorias do desenvolvimento pessoal da psicologia.

Segundo Illouz, feminismo e psicanálise, apesar de suas oposições, formam, na prática, uma narrativa moral única da intimidade. A retirada cada vez mais efetiva dos sentimentos da esfera privada e a consequente transformação das questões da intimidade em problemas públicos são frutos, em boa medida, da atuação e do alcance institucional logrados pelo feminismo e pela psicanálise. Ao passo que, a literatura de autoajuda do século XX, imbuída da linguagem do "eu ferido", promoveu uma fundamental mudança na articulação da identidade moral da individualidade ao moldá-la como uma narrativa de sofrimento psíquico.

A apropriação do discurso terapêutico por esses repertórios contribuiu para a difusão e consolidação desta forma particular de compreensão e de mobilização do "eu”, cuja vocação consiste em manejar as emoções "por meio de uma narrativa que combina a aspiração à autorrealização com o direito ao sofrimento" (Ibid., p. 12).

A linguagem terapêutica do "eu" como conduta objetificante da vida afetiva converte-se numa linguagem cultural onipresente. Ela é institucionalizada, de acordo com Illouz, em práticas culturais e espaços sociais tão distintos como programas de talkshow, programas de reabilitação, seminários remunerados, manuais de consultores e sites de relacionamento. Todos eles "lugares para atuação e reatualização do eu” (Ibid., p. 72).

A presença do credo terapêutico em instituições sociais estratégicas confere-lhe mais do que poder e legitimidade sobre as condutas dos indivíduos. Ela introduz maneiras de agir e de pensar. O estilo afetivo terapêutico opera como uma estrutura cognitiva e prática. Por isso, o domínio das aptidões e competências conformadas ao seu ethos, afirma Illouz, é decisivo em relação à competição social. Ele oferece vantagens competitivas para a posse de bens morais e formas de bem-estar socialmente almejados, como a autorrealização, a felicidade e a saúde afetiva ou para o desempenho e êxito no mundo das empresas e das relações amorosas.

Portanto, conclui Illouz, o estilo afetivo terapêutico configura-se, nas sociedades avançadas, como uma linguagem da identidade e como uma forma de capital que produz novas modalidades de desigualdade e estratificação.

$\mathrm{Na}$ conferência de encerramento, Illouz busca apreender como as relações românticas e a atração amorosa são organizadas pela tecnologia da internet.

Investigando famosos sites de encontros e relacionamentos, a autora aborda o impacto da internet sobre as interações amorosas e a cultura do amor. A partir de entrevistas com usuários 
destes sites, Illouz sugere que as ideias e categorias culturais da tradição do romantismo sofrem uma inflexão radical com a consolidação da internet e o advento dos sítios de relacionamentos. Mudanças observadas, sobretudo, nos modos de apresentação do "eu" e no papel dos afetos, do "sentir" e na formação dos laços amorosos.

Desvinculado de contatos corporais e de um pano de fundo existencial tácito, o amor na internet, de acordo com Illouz, germina a partir do "conhecer". Na imaginação e na sociabilidade que a internet promove, a organização da fantasia e dos afetos da atração amorosa depende de um processo intelectivo, apto a tratar e traduzir comportamentos, atributos e sentimentos na forma de dados, sinais e signos emitidos por perfis e trocados em interações textuais e visuais descorporificadas. Nestes sítios de relacionamento, "primeiro as pessoas são apreendidas como um conjunto de atributos, e só depois apreendem - em etapas gradativas - a presença corpórea do outro" (Ibid., p. 113).

A mobilização da psicologia, a utilização de procedimentos racionalizadores e a referência à semântica do mercado modulam a experiência amorosa, as interações e a organização social desses espaços virtuais.

$\mathrm{Na}$ configuração social dos sítios de relacionamento, assinala Illouz, nota-se o poder de estruturação e de enquadramento dos modos de agir e pensar do mercado. O espírito e a lógica da rede seguem claramente princípios típicos da racionalidade da esfera da troca de mercadorias e do mercado capitalistas, tais como; abundância, escolha ampla, valor, competição e desempenho. "O resultado é que o vocabulário dos afetos é hoje mais do que exclusivamente ditado pelo mercado", assegura Illouz (Ibid., p. 130-1).

A mediação tecnológica e cultural da internet na esfera das trocas amorosas alça o processo de construção de uma subjetividade afetiva cada vez mais publicamente encenada e objetificada a um patamar ainda mais evidente, observa Ilouz.

Para a socióloga, os sites de encontros e de relacionamentos constituem a síntese contemporânea do processo de racionalização dos afetos posto em marcha pela psicologia e o credo terapêutico. É nesse ponto, em particular, que Illouz avança de uma maneira mais crítica do que o diagnóstico da intimidade moderna proposto por Giddens (1994).

Illouz não perde de vista o fato de que os repertórios culturais e agentes sociais responsáveis por elevar as relações afetivas a um plano de maior igualdade, individualização e emancipação, também produziram um "vasto processo de racionalização das relações íntimas" (ILLOUZ, 2011, p. 47). 
A veia crítica do projeto sociológico de Eva Illouz recai, precisamente, sobre as consequências desse processo. O triunfo cultural do estilo afetivo terapêutico, isto é, a difusão e institucionalização de instrumentos e práticas racionais de classificação e objetificação da conduta afetiva em diversas esferas da vida, redundou numa intelectualização dos vínculos afetivos e dos afetos. Consolida-se, assim, uma despersonalização dos sentimentos, a "ideia de que os sentimentos podem ser desligados do sujeito para controle e esclarecimento" (Ibid., p. 55).

Porém, o diagnóstico crítico de Illouz, ainda que flerte com os quadros mais cinzentos e desoladores da modernidade, de Weber e Simmel a Adorno e Horkheimer, não se deixa, entretanto, seduzir pelo canto de sereia da Teoria Crítica e seus excessos valorativos.

Se, por um lado, Illouz concorda que o estilo afetivo terapêutico condiciona a experiência dos afetos a critérios e léxicos racionalizadores e neutros, acarretando sua objetificação e textualização, por outro, num gesto fiel ao pragmatismo, ela sustenta: "Para ser eficaz, um discurso deve realizar certas coisas para as pessoas que confiam nele e o utilizam” (Ibid., p. 97).

A hegemonia e o alcance do estilo afetivo terapêutico se devem também a sua capacidade de ofertar práticas e recursos que promovem os desejos e as necessidades das pessoas. Ele proporciona modos de lidar e de refletir com os quais as pessoas enfrentam situações problemáticas no fluxo instável das relações sociais e da experiência subjetiva da modernidade tardia.

Por fim, dentre as críticas ao livro, cabe destacar uma que, em particular, me parece relevante: a escassa presença de Norbert Elias. Illouz passa ao largo das análises do sociólogo alemão sobre as transformações na economia emocional das sociedades na modernidade. Sem se importar em discutir as possíveis relações entre o processo civilizador ocidental descrito por Elias e o estilo afetivo terapêutico.

O trabalho de Elias (1994) ao analisar o desenvolvimento crescente de um maior domínio e autocontrole dos impulsos emocionais, relacionando-o com grandes processos de mudanças institucionais no âmbito do Estado, se cotejado com o livro de Illouz, pode lançar luz sobre aspectos pouco examinados neste último, tais como: o papel do poder político e das mudanças dos equilíbrios de poder e das formas institucionais do Estado na constituição e desenvolvimento do estilo afetivo terapêutico. 
À despeito desse déficit, o leitor encontrará nas análises de Illouz, uma socióloga afinada com o patrimônio teórico da disciplina. Autores e abordagens de diferentes tradições sociológicas, como Pierre Bourdieu, Erving Goffman e a Teoria Crítica comparecem, com engenhosidade e aplicação crítica, no labor interpretativo da autora. Desse modo, sua abordagem resulta numa perspectiva que lhe permite avaliar diferentes dimensões das transformações que a psicologia e a linguagem da terapia em seu entrelaçamento com a racionalidade capitalista provocaram na sociabilidade e na experiência do "eu" nas sociedades avançadas contemporâneas.

\section{Referências Bibliográficas}

ELIAS, Norbert. O Processo Civilizador: uma história dos costumes. Rio de Janeiro: Jorge Zahar, 1994. V.1.

. A Solidão dos Moribundos. Rio de Janeiro: Jorge Zahar, 2001.

FOUCAULT, Michel. A verdade e as formas jurídicas. Rio de Janeira: Editora Nau, 2002.

GIDDENS, Anthony. A transformação da intimidade. São Paulo: Ed. Unesp, 1994.

ILLOUZ, Eva. O amor nos tempos do capitalismo. Trad. Vera Ribeiro. Rio de Janeiro: Zahar, 2011.

LUHMANN, Niklas. O amor como paixão. Lisboa: Difel. 1991.

ZELIZER, Viviane. A negociação da intimidade. Petrópolis: Ed. Vozes, 2011. 